\title{
Influence of Carbon Black Structure and Specific Surface Area on the Mechanical and Dielectric Properties of Filled Rubber Composites
}

\author{
Omar A. Al-Hartomy, ${ }^{1,2}$ Falleh Al-Solamy, ${ }^{3}$ Ahmed Al-Ghamdi, ${ }^{2}$ Nikolay Dishovsky, ${ }^{4}$ \\ Milcho Ivanov, ${ }^{4}$ Mihail Mihaylov, ${ }^{4}$ and Farid El-Tantawy ${ }^{5}$ \\ ${ }^{1}$ Department of Physics, Faculty of Science, University of Tabuk, Tabuk 71491, Saudi Arabia \\ ${ }^{2}$ Department of Physics, Faculty of Science, King Abdulaziz University, Jeddah 21589, Saudi Arabia \\ ${ }^{3}$ Department of Mathematics, Faculty of Science, University of Tabuk, Tabuk 71491, Saudi Arabia \\ ${ }^{4}$ Department of Polymer Engineering, University of Chemical Technology and Metallurgy, 1756 Sofia, Bulgaria \\ ${ }^{5}$ Department of Physics, Faculty of Science, Suez Canal University, Ismailia, Egypt \\ Correspondence should be addressed to Mihail Mihaylov, m_c_mihaylov@abv.bg
}

Received 28 May 2011; Revised 26 July 2011; Accepted 26 July 2011

Academic Editor: Peng He

Copyright ( $) 2011$ Omar A. Al-Hartomy et al. This is an open access article distributed under the Creative Commons Attribution License, which permits unrestricted use, distribution, and reproduction in any medium, provided the original work is properly cited.

\begin{abstract}
Natural rubber based composites have been prepared using various amounts of two fillers: conventional Corax N220 carbon black or electrically conductive carbon black Printex XE-2B which has a very high specific surface area. The composites have been studied by dynamic mechanical thermal analysis, dielectric thermal analysis and SEM. It has been established that all vulcanizates investigated are in the glass state in the $-80^{\circ} \mathrm{C}$ to $-40^{\circ} \mathrm{C}$ interval. The storage modulus increases with the increasing filler content in the $-40^{\circ} \mathrm{C}$ to $+80^{\circ} \mathrm{C}$ interval when the vulcanizates are in the highly elastic state. DETA shows that the increase in filler content leads to an increase in the dielectric permittivity $\left(\varepsilon^{\prime}\right) . \varepsilon^{\prime}$ also increases with temperature increasing. Higher frequency causes a decrease of $\varepsilon^{\prime}$ values which becomes more pronounced with the increasing filler content. Obviously, when the content of Printex $\mathrm{XE}-2 \mathrm{~B}$ carbon black in the vulcanizates is higher than $7.5 \mathrm{phr}$, the percolation threshold is reached and the $\varepsilon^{\prime}$ values increase up to $10^{2}-10^{4}$. The $\varepsilon^{\prime}$ values for the vulcanizates comprising 20 and 50 phr Corax N220 carbon black are measurable with those for the vulcanizates comprising 5 and 10 phr Printex XE-2B carbon black respectively. The results obtained could be explained by the difference in the structure and specific surface area of the two types of carbon black-Printex XE-2B and Corax N220.
\end{abstract}

\section{Introduction}

Natural rubber (NR), produced by Hevea Brasiliensis whose chemical structure is cis-1.4-polyisoprene, possesses excellent physical properties of a general purpose rubber. Presently, conventional carbon black (N220, N330, N550, etc.) is its outstanding reinforcing filler [1]. NRcarbon-black-filled vulcanizates are characterized by high mechanical strength, remarkable resilience, excellent elasticity, abrasion resistance, good low heat built-up, and good dynamic properties [2] but they do not have the electrical and magnetic properties needed for some more special applications.
With the development of electronic industry, some special dielectric materials with high and/or low dielectric permittivity are attracting notable attention of the academic and industrial circles. The dielectric properties of the insulation materials could be adjusted by dispersing different kinds of fillers into the polymer matrices, for example, the dielectric permittivity of the resulting composites is determined by the low or high dielectric permittivity of the inorganic or organic fillers added [3]. Moreover, the dielectric permittivity of polymer/filler composites could be changed by altering the filler concentration.

Evonik Industries AG has been the renowned world leader in the production of organic and mineral fillers. 
TABLE 1: Typical properties of the carbon black used.

\begin{tabular}{lccccc}
\hline Carbon black & $\begin{array}{c}\text { Iodine adsorption* } \\
\mathrm{mg} / \mathrm{g}\end{array}$ & $\begin{array}{c}\text { CTAB-surface area** } \\
\mathrm{m}^{2} / \mathrm{g}\end{array}$ & $\begin{array}{c}\text { BET surface area*** } \\
\mathrm{m}^{2} / \mathrm{g}\end{array}$ & $\begin{array}{c}\text { DBP-absorption } \\
\mathrm{mL} / 100 \mathrm{~g}\end{array}$ & $\begin{array}{c}\text { CDBP absorption } \\
\mathrm{mL} / 100 \mathrm{~g}\end{array}$ \\
\hline $\begin{array}{l}\text { Corax N 220 } \\
\text { Printex }\end{array}$ & 121 & 96 & 105 & 98 & 70 \\
XE-2B & 1091 & 600 & 1000 & 403 & 370 \\
\hline
\end{tabular}

* The iodine number (iodine adsorption) reflects a "not true" surface area, because it is affected by porosity, surface impurities, and surface oxidation. $* *$ The cetyltrimethyl ammonium bromide (CTAB) surface area analyzes the so-called external surface area which corresponds to the accessible surface area for an elastomer. $* * *$ BET (Brunauer, Emmett, and Teller) nitrogen adsorption surface area provides the "total" surface area including porosity.

Printex XE-2B carbon black is one of their latest interesting developments which has already been placed on the marked. According to company's literature sources, Printex XE-2B is furnace carbon black, obtained by a technology which is a company secret. The product is characterized by a very high specific surface area $\left(600 \mathrm{~m}^{2} / \mathrm{g}\right)$ and by a very high electrical conductivity, uncharacteristic of the classical types of furnace carbon black (N550, N330, N220, etc.).

Regarding the above said, the investigations undertaken aimed at studying the vulcanization characteristics, mechanical parameters, and dynamic and dielectric properties of natural rubber-based composites comprising various amounts of the electrically conductive Printex XE-2B carbon black having a very high specific surface area.

\section{Experimental}

2.1. Characterization of the Carbon Black Used. Two types of carbon black absolutely different in their specific surface area and structure were chosen for the experiments: furnace carbon black Corax N220 and extra conductive black Printex XE-2B (both produced by Evonik). The most important characteristics of the two types of carbon black are summarized in Table 1.

The primary particles formed during the initial carbon black formation stage fuse together building up threedimensional branched clusters called aggregates. High structure carbon black has a high number of primary particles per aggregate, while low structure carbon black exhibits only a weak aggregation. These aggregates again may form agglomerates linked by Van der Waals interactions. The empty space (void volume) between the aggregates and agglomerates usually expressed as the volume of dibutylphtalate (DBP) absorbed by a given amount of carbon black is described by the term "structure" (or "structurality") of the carbon black. It is assumed that DBP absorption reflects the total carbon black structure which comprises both aggregates and agglomerates, whereas the crushed DBP (CDBP) absorption test eliminates loose agglomerates and easily destroyable aggregates.

\subsection{Preparation and Vulcanization of Rubber Compounds.} The studies were performed on rubber compounds (in phr) summarized in Table 2.

The rubber compounds were prepared by an open tworoll laboratory mill (L/D $320 \times 360$ and friction 1.27$)$. The speed of the slow roll was $25 \mathrm{~min}^{-1}$. The formulations of the compounds prepared are shown in Table 2. The experiments were repeated for verifying the statistical significance. The ready compounds in the form of sheets stayed 24 hours prior to their vulcanization.

The optimal curing time $\left(\mathrm{T}_{90}\right)$ was determined by the vulcanization isotherms, taken on an oscillating disc vulcameter MDR 2000 (Alpha Technologies) at $150^{\circ} \mathrm{C}$, according to ISO 3417:2002.

\subsection{Measurements}

2.3.1. Mechanical Properties. The mechanical properties of the vulcanizates of the rubber compounds studied were determined according to ISO 37:2002.

2.3.2. Dynamic Mechanical Thermal Analysis (DMTA). Dynamic properties (Storage modulus $\left(\mathrm{E}^{\prime}\right)$ ) and mechanical loss angle tangent $(\tan \delta)$ of the natural rubber based vulcanizates were investigated using a Dynamic Mechanical Thermal Analyzer Mk III system (Rheometric Scientific). The data were obtained at $5 \mathrm{~Hz}$ frequency, $64 \mu \mathrm{m}$ strain in the temperature range from $-80^{\circ} \mathrm{C}$ to $80^{\circ} \mathrm{C}$ using a heating rate of $3^{\circ} \mathrm{C} / \mathrm{min}$ under single cantilever bending mode. The dimensions of the investigated samples were as follows: width $10 \mathrm{~mm}$, length $25 \mathrm{~mm}$, and the thickness measured using a micrometer varied between 1 and $2 \mathrm{~mm}$.

2.3.3. Dielectric Thermal Analysis (DETA). Dielectric properties (Permittivity $\left(\varepsilon^{\prime}\right)$ ) and dielectric loss angle tangent (DETA $\tan \delta$ ) were investigated using a Dielectric Thermal Analyzer (Rheometric Scientific) at four different frequencies $(1 \mathrm{kHz}, 10 \mathrm{kHz}, 100 \mathrm{kHz}$, and $1 \mathrm{MHz})$ in the temperature range between $20^{\circ} \mathrm{C}$ and $100^{\circ} \mathrm{C}$. The sample had a diameter of approximately $32 \mathrm{~mm}$ and was $1 \mathrm{~mm}$ thick.

2.3.4. Scanning Electron Microscopy (SEM). The composition microstructure of the vulcanizates was investigated by SEM micrographs taken on a JEOL JSM-5510 scanning electron microscope.

\section{Results and Discussion}

3.1. Curing Properties. Table 3 summarizes the curing properties of the studied rubber compounds.

As the table shows, the increase in filler concentration (Printex XE-2B or Corax N220 carbon black) leads to an increase in the values of minimum (ML) and maximum 
TABle 2: Composition of the rubber compounds studied.

\begin{tabular}{lcccccccc}
\hline & NR1 & NR2 & NR3 & NR4 & NR5 & NR6 & NR7 & NR8 \\
\hline Natural Rubber (NR) & 100 & 100 & 100 & 100 & 100 & 100 & 100 & 100 \\
ZnO & 5 & 5 & 5 & 5 & 5 & 5 & 5 & 5 \\
Stearic Acid & 2 & 2 & 2 & 2 & 2 & 2 & 2 & 2 \\
Printex XE-2B Carbon Black & - & 5 & 7.5 & 10 & 15 & 20 & - & - \\
Corax N220 Carbon Black & - & - & - & - & - & - & 20 & 50 \\
TBBS* & 0.8 & 0.8 & 0.8 & 0.8 & 0.8 & 0.8 & 0.8 & 0.8 \\
Sulfur & 2.25 & 2.25 & 2.25 & 2.25 & 2.25 & 2.25 & 2.25 & 2.25 \\
\hline
\end{tabular}

* TBBS: N-tert-Butyl-2-benzothiazolesulfenamide.

TABLE 3: Curing properties of the investigated rubber compounds at $150^{\circ} \mathrm{C}$.

\begin{tabular}{lcccccccc}
\hline & NR1 & NR2 & NR3 & NR4 & NR5 & NR6 & NR7 & NR8 \\
\hline $\mathrm{ML}, \mathrm{dNm}$ & 0.15 & 0.36 & 0.25 & 0.50 & 1.74 & 2.99 & 0.35 & 1.56 \\
$\mathrm{MH}, \mathrm{dNm}$ & 9.90 & 12.41 & 12.00 & 14.11 & 20.25 & 25.09 & 13.23 & 24.35 \\
$\Delta \mathrm{M}=\mathrm{MH}-\mathrm{ML}$ & 9.75 & 12.05 & 11.75 & 13.61 & 18.51 & 22.1 & 12.88 & 22.79 \\
$\mathrm{~T}_{\mathrm{s} 2}, \mathrm{~min}: \mathrm{s}$ & $4: 21$ & $3: 03$ & $3: 10$ & $2: 54$ & $2: 21$ & $1: 49$ & $2: 38$ & $2: 16$ \\
$\mathrm{~T}_{90}, \mathrm{~min}: \mathrm{s}$ & $8: 02$ & $8: 26$ & $7: 46$ & $8: 47$ & $9: 29$ & $10: 20$ & $7: 30$ & $7: 34$ \\
Curing rate, $\mathrm{V}, \% / \min$ & 27 & 21 & 19 & 17 & 14 & 12 & 21 & 19 \\
\hline
\end{tabular}

torque $(\mathrm{MH})$ which reveal the viscosity and hardness of the rubber compounds. However, noteworthy is the fact that those values for the compound comprising Corax N220 carbon black at $20 \mathrm{phr}$ are measurable with those for the compounds comprising Printex XE-2B carbon black at 5 and $7.5 \mathrm{phr}$, respectively. The same values for the compound comprising Corax N220 carbon black at $50 \mathrm{phr}$ are measurable with those for the compound comprising Printex $\mathrm{XE}-2 \mathrm{~B}$ at $15 \mathrm{phr}$. Though the optimum curing time $\left(\mathrm{T}_{90}\right)$ gets longer at Printex XE-2B carbon black concentrations higher than $7.5 \mathrm{phr}$, it can be stated that the dependence $\mathrm{T}_{90}$ versus filler content does not differ considerably for all the composite studied. The same is not valid for the scorch time $\left(T_{\mathrm{s} 2}\right)$ values which decrease considerably with the increasing concentration of Printex XE-2B carbon black. The increase in the concentration of Corax N220 carbon black does not affect $T_{s 2}$ of the rubber compounds thus filled. The obtained results for the curing properties of the investigated rubber compounds can be explained by the great difference in the structure and specific surface area of the two types of fillers.

3.2. Mechanical Properties. Table 4 presents the main mechanical properties of the vulcanizates of the studied rubber compounds. As seen from the table, the higher amount of both fillers causes an increase in the modulus at $100 \%$ and modulus at $300 \%$ elongation $\left(\mathrm{M}_{100}\right.$ and $\left.\mathrm{M}_{300}\right)$, while, as expected, the relative and residual deformation decrease. In the case of the vulcanizates comprising Printex $\mathrm{XE}-2 \mathrm{~B}$ carbon black, the tensile strength values initially increase slightly, while at filler content higher than $5 \mathrm{phr}$ the values of the parameter decrease about $10-15 \%$. The tensile strength of the vulcanizates comprising Corax N220 increases negligibly with the increasing filler amount.
The values of the tensile strength for the vulcanizates comprising 7.5, 10, 15, and $20 \mathrm{phr}$ Printex XE-2B carbon black are lower than those for the vulcanizates comprising Corax N220. At a first glimpse such values seem atypical for vulcanizates of natural rubber filled with carbon black. However, the references showed that the obtained values do not differ much from those cited in the company literature data about vulcanizates of natural rubber filled with same carbon black at the same concentrations. We assume the observed effects to be due to the different texture of the two types of carbon black. Our previous studies [4] demonstrated that the following texture characteristics of carbon black determine its effect upon the properties of compounds and vulcanizates: specific surface area $\left(\mathbf{A}_{\mathrm{BET}}\right)$; total pore volume $\left(\mathbf{V}_{\mathbf{t}}\right)$; micropore volume $\left(\mathbf{V}_{\mathbf{M I}}\right)$; mesoporespecific surface area $\left(\mathbf{A}_{\mathrm{MES}}\right)$; mesopore volume $\left(\mathbf{V}_{\mathrm{ME}}\right)$, calculated by subtracting total micropore volume $\left(\mathbf{W}_{\mathbf{O}}\right)$ from $\mathbf{V}_{\mathbf{t}}$; the average micropore radius $\left(\mathbf{r}_{\mathrm{P}}\right)$, as a $2 \mathbf{V}_{\mathrm{ME}} / \mathbf{A}_{\mathrm{MES}}$ ratio; mesopores size distribution; supermicropore volume $\left(\mathbf{V}_{\mathrm{SMI}}=\mathbf{W}_{\mathbf{O}}-\mathbf{V}_{\mathbf{M I}}\right)$ and micropore half-width.

So far no direct dependence of the vulcanizates curing and mechanical properties on the texture parameters has been established. However, comparing the results for the samples comprising different types of carbon black, one sees that the texture parameters do have some effect and that does not concern only the differences in BET-and CTAB-specific surface areas. On the other hand, our investigations confirm the dominating assumption that micropores (submicroand supermicro-) have a great merit to the formation of BET-specific surface area values. Micropores higher concentrations worsen the physicochemical and mechanical properties of the vulcanizates; that is, due to their major characteristic parameter (half-width), which is relatively 
TABLE 4: Mechanical properties of the investigated vulcanizates.

\begin{tabular}{|c|c|c|c|c|c|c|c|c|}
\hline & NR1 & NR2 & NR3 & NR4 & NR5 & NR6 & NR7 & NR8 \\
\hline $\mathrm{M}_{100}, \mathrm{MPa}$ & 0.8 & 1.2 & 1.2 & 1.4 & 2.1 & 3.5 & 2.6 & 3.8 \\
\hline $\mathrm{M}_{300}, \mathrm{MPa}$ & 2.7 & 3.2 & 4.5 & 4.8 & 8.3 & 12.2 & 9.3 & 10.8 \\
\hline Tensile strength, $\mathrm{MPa}$ & 17.7 & 18.5 & 15.2 & 16.5 & 16.1 & 15.5 & 18.5 & 19.2 \\
\hline Elongation at break, \% & 740 & 680 & 530 & 520 & 500 & 440 & 650 & 550 \\
\hline Residual elongation, \% & 15 & 15 & 10 & 10 & 10 & 10 & 10 & 10 \\
\hline Shore A hardness & 50 & 52 & 53 & 56 & 61 & 67 & 60 & 65 \\
\hline
\end{tabular}

small and hampers their volume filling (e.g., with adsorbed elastomer macromolecules); hence there are less possibilities of elastomer-filler interactions [5].

In our opinion, the volume and the size distribution of the pores are the texture parameters having the most important impact over the reinforcement effect of the studied fillers regarding the physicochemical properties of the vulcanizates. The parameters mentioned benefit the possible elastomerfiller contacts at the different sites of the nanoporous texture, as a whole that affects the elastomer-filler interactions. Usually the real mesopores have constraints which can be blocked easily (e.g., by the adsorbed molecules of the accelerator (or activator) of the vulcanization process). In order to use the maximum of the specific surface area for interaction with the elastomer molecules, the mesopores should be of their maximum average radius and volume. Obviously, of the nature of Corax N220, carbon black benefits the elastomer-filler interactions at a higher extent than that of Printex XE-2B carbon black. Last but not least, there is an optimal average radius of the mesopores which facilitates the so-called "mobile adsorption", that is, the possibility of the elastomer molecules to move to the filler surface from a certain sorption site to another. According to Danneberg [5], the latter fact is of a great importance for the fillers reinforcement effect. Hence, the part of the specific surface area of the fillers (in the case the two types of carbon black studied) available for interaction with the elastomer molecules is determined by different factors, with the mesopores average radius and volume included. However, a definite proof of the said hypothesis requires additional studies on the texture characteristics of the two types of carbon black. However, whenever using Printex XE-2B carbon black and studying vulcanizates thus filled, one should have in mind that this filler possesses unique properties compared to the classical carbon black (N220, N300, N550). As Table 1 shows, first of all those are the very high structure, high specific surface area, and surface chemistry.

3.3. Dynamic Mechanical Thermal Analysis (DMTA). Figures 1 and 2 present the dependences of storage modulus $\left(E^{\prime}\right)$ and dynamic mechanical loss angle tangent $(\tan \delta)$ on the filler amount and type, studied in the temperature interval from $-80^{\circ} \mathrm{C}$ to $+80^{\circ} \mathrm{C}$. As the figure shows, in the $-80^{\circ} \mathrm{C}$ to $-40^{\circ} \mathrm{C}$ interval no considerable changes occur in the storage modulus $\left(\mathrm{E}^{\prime}\right)$. Though it is worth mentioning that the storage modulus $\left(\mathrm{E}^{\prime}\right)$ values of the vulcanizates comprising

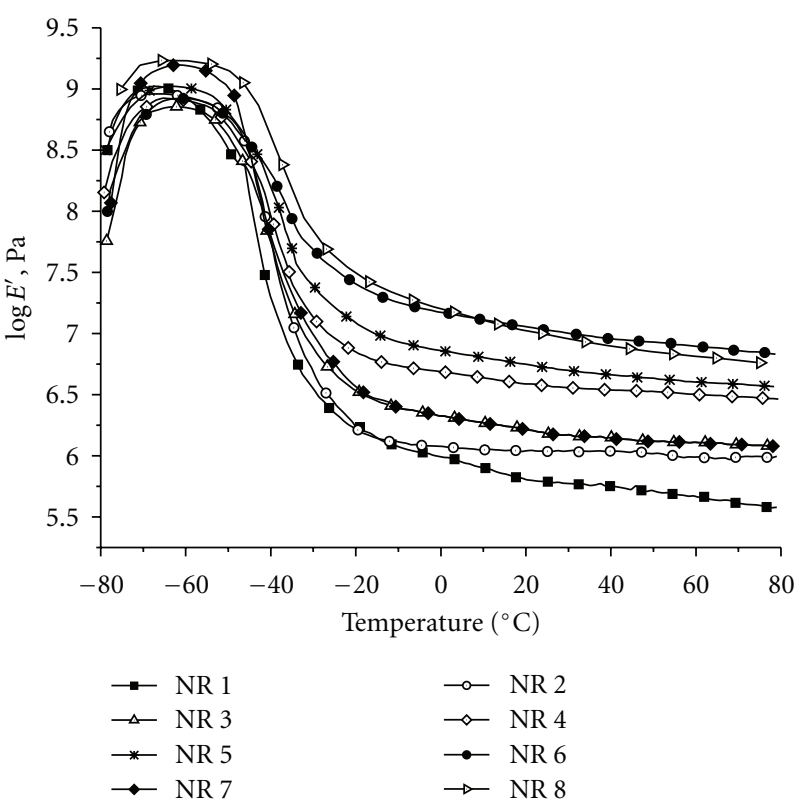

Figure 1: Temperature dependence of the storage modulus $\left(E^{\prime}\right)$ for composites comprising different amounts of Printex XE-2B or Corax N220.

Corax N220 (NR 7 and NR 8) are a little higher than those of the vulcanizates comprising Printex XE-2B (NR 1 to NR $6)$. The decrease of storage modulus $\left(E^{\prime}\right)$ with the increasing temperature, that is, the transition from the glass to the high elastic state occurs at about $-40^{\circ} \mathrm{C}$. In the interval from $-40^{\circ} \mathrm{C}$ to $+80^{\circ} \mathrm{C}$ when the vulcanizates studied are in the high elastic state, the storage modulus $\left(\mathrm{E}^{\prime}\right)$ values increase with the increasing filler amount, that is due to the limited mobility of rubber macromolecules, being immobilized onto the carbon black surface. Accordingly [6], this effect may be used as a measure for fillers reinforcing activity, because the greater the reinforcing activity of the filler, the lesser the mobility and the higher storage modulus $\left(\mathrm{E}^{\prime}\right)$ values. Similarly to the tendency of the mechanical properties, the storage modulus $\left(\mathrm{E}^{\prime}\right)$ values for the vulcanizates comprising 20 phr Corax N220 carbon black (NR 7) are measurable with those for the vulcanizates comprising 7.5 phr Printex XE-2B carbon black (NR 3). On the other hand, storage modulus $\left(\mathrm{E}^{\prime}\right)$ values for the vulcanizates comprising $50 \mathrm{phr}$ Corax N220 carbon black (NR 8) are measurable with those for the vulcanizates comprising 20 phr Printex XE-2B carbon black 


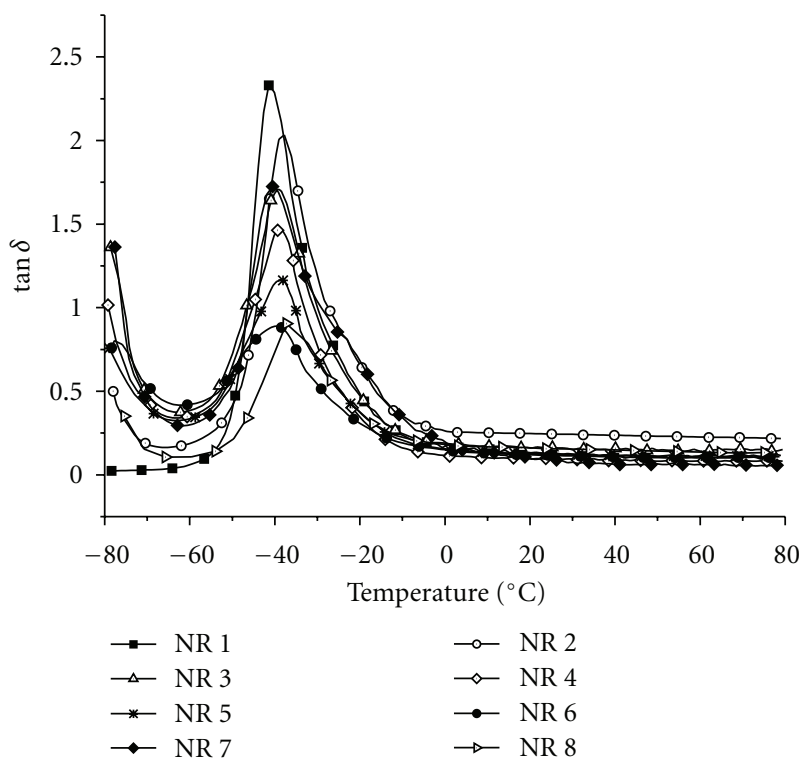

Figure 2: Temperature dependence of the mechanical loss angle tangent $(\tan \delta)$ for composites comprising different amounts of Printex XE-2B or Corax N220.

(NR 6). The effects in the case are particularly pronounced, which could be explained again by the great specific surface area of Printex XE-2B carbon black (about $600 \mathrm{~m}^{2} / \mathrm{g}$ ).

The mechanical loss angle tangent is the ratio between the dynamic loss modulus $\left(\mathrm{E}^{\prime \prime}\right)$ and the dynamic storage modulus $\left(\mathrm{E}^{\prime}\right)\left(\tan \delta=\mathrm{E}^{\prime \prime} / \mathrm{E}^{\prime}\right)$. It represents the macromolecules mobility and polymers phase transitions [7]. As seen from Figure 2, in the interval from $0^{\circ} \mathrm{C}$ to $+80^{\circ} \mathrm{C}$ the amount and type of the fillers used do not cause significant differences in $\tan \delta$ values. It is known that $\tan \delta$ peak corresponds to the glass transition temperature $\left(\mathrm{T}_{\mathrm{g}}\right)$ of the composite. Figure 2 shows that the glass transition temperature $\left(\mathrm{T}_{\mathrm{g}}\right)$ of the vulcanizates studied does not change considerably (within the limits of $2-3^{\circ} \mathrm{C}$ ) upon a change in the amount and type of the fillers used. However, the increase in the content of the fillers used leads to a decrease of the intensity of the peak at $\tan \delta$, which could be explained by the reinforcement effect of carbon black [8].

3.4. Dielectric Thermal Analysis (DETA). Figures 3 and 4 plot the frequency dependence of the dielectric permittivity $\left(\varepsilon^{\prime}\right)$ of the investigated natural rubber-based vulcanizates comprising various amounts of Printex XE-2B or Corax $\mathrm{N} 220$ carbon black, studied at $30^{\circ} \mathrm{C}$ and $80^{\circ} \mathrm{C}$, respectively.

As seen from Figure 3, the values for dielectric permittivity $\left(\varepsilon^{\prime}\right)$ for the vulcanizates filled with Printex XE-2B carbon black at $7.5 \mathrm{phr}$ are close to those for nonfilled ones. In this case, the vulcanizates comprising 7.5 phr Printex XE2B carbon black behave as dielectrics, and their dielectric permittivity $\left(\varepsilon^{\prime}\right)$ is determined by the elastomer matrix and its values do not change considerably with the frequency increasing. Obviously, when the content of Printex XE-2B carbon black in the vulcanizates is higher than $7.5 \mathrm{phr}$, the percolation threshold is reached and passed over. Then the

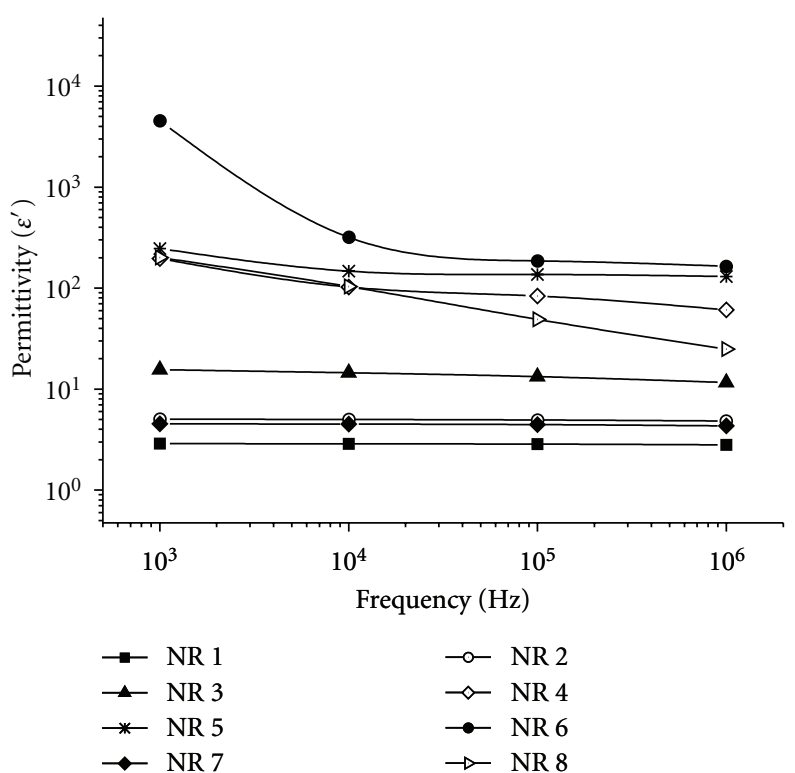

FIGURE 3: Frequency dependence of the dielectric permittivity $\left(\varepsilon^{\prime}\right)$ for composites comprising different amounts of Printex XE-2B or Corax N220 at $30^{\circ} \mathrm{C}$.

dielectric permittivity $\left(\varepsilon^{\prime}\right)$ values increase up to $10^{2}-10^{4}$. In the case the frequency increase leads to a decrease of dielectric permittivity $\left(\varepsilon^{\prime}\right)$ values. The $\left(\varepsilon^{\prime}\right)$ values for the vulcanizates comprising $20 \mathrm{phr}$ Corax N220 carbon black are measurable with those for the vulcanizates comprising $5 \mathrm{phr}$ Printex XE-2B carbon black and do not change considerably at higher frequency. The dielectric permittivity $\left(\varepsilon^{\prime}\right)$ values for the vulcanizates comprising $50 \mathrm{phr}$ Corax N220 carbon black are measurable with those for the vulcanizates comprising $10 \mathrm{phr}$ Printex XE-2B carbon black. Probably, in that case the percolation threshold has been reached, although the dielectric permittivity $\left(\varepsilon^{\prime}\right)$ values for the vulcanizates comprising 50 phr Corax N220 carbon black are considerably lower than those for the vulcanizates comprising 15 and $20 \mathrm{phr}$ Printex XE-2B carbon black. The effects in the case are particularly pronounced which could be explained again by the much larger specific surface area of Printex XE-2B carbon black (about $600 \mathrm{~m}^{2} / \mathrm{g}$ ) if compared to the one of Corax N220 carbon black N220 $\left(96 \mathrm{~m}^{2} / \mathrm{g}\right)$. The larger specific surface area of Printex XE-2B carbon black facilitates more pronounced interactions between the filler particles. It also benefits the filler-matrix interaction. Therefore, vulcanizates comprising Printex XE-2B carbon black have dielectric permittivity $\left(\varepsilon^{\prime}\right)$ values higher than those of the vulcanizates filled with a much greater amount of Corax N220 carbon black.

As seen from Figure 4 , at $80^{\circ} \mathrm{C}$ the tendency in the dependence of composites dielectric permittivity $\left(\varepsilon^{\prime}\right)$ on frequency and filler amount remains the same as the one at $30^{\circ} \mathrm{C}$, though in that case the dielectric permittivity $\left(\varepsilon^{\prime}\right)$ values are much higher. At $80^{\circ} \mathrm{C}$ the dielectric permittivity $\left(\varepsilon^{\prime}\right)$ values increase in about 2 orders in comparison to those at $30^{\circ} \mathrm{C}$ (Figure 3 ). There is also an independent tendency at a higher filler concentration (15 and $20 \mathrm{phr}$ ). With the increasing frequency, the dielectric permittivity $\left(\varepsilon^{\prime}\right)$ values 


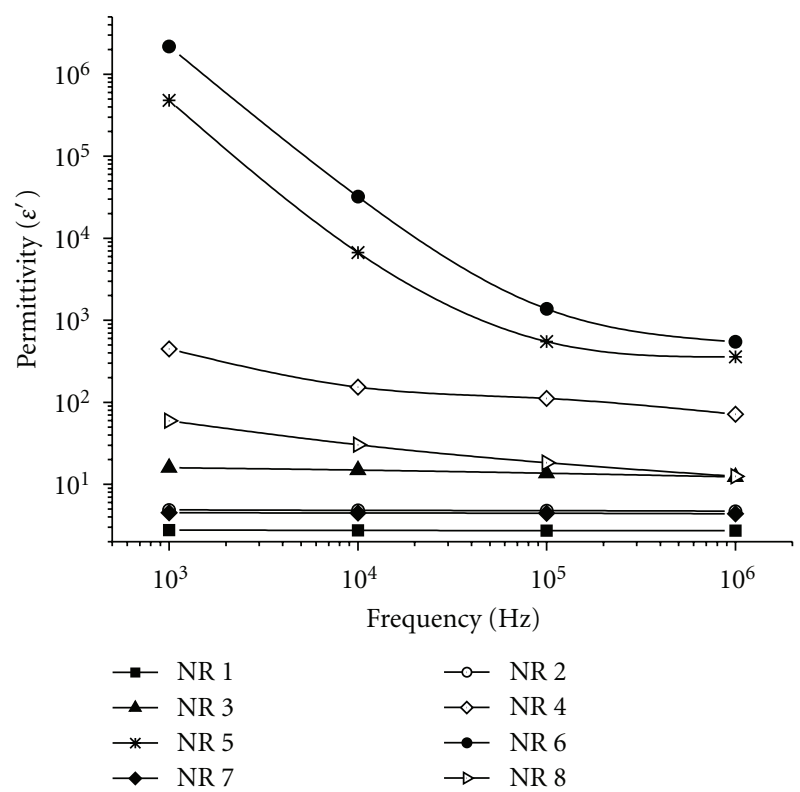

FIgURE 4: Frequency dependence of the dielectric permittivity $\left(\varepsilon^{\prime}\right)$ for composites comprising different amounts of Printex XE-2B or Corax $\mathrm{N} 220$ at $80^{\circ} \mathrm{C}$.

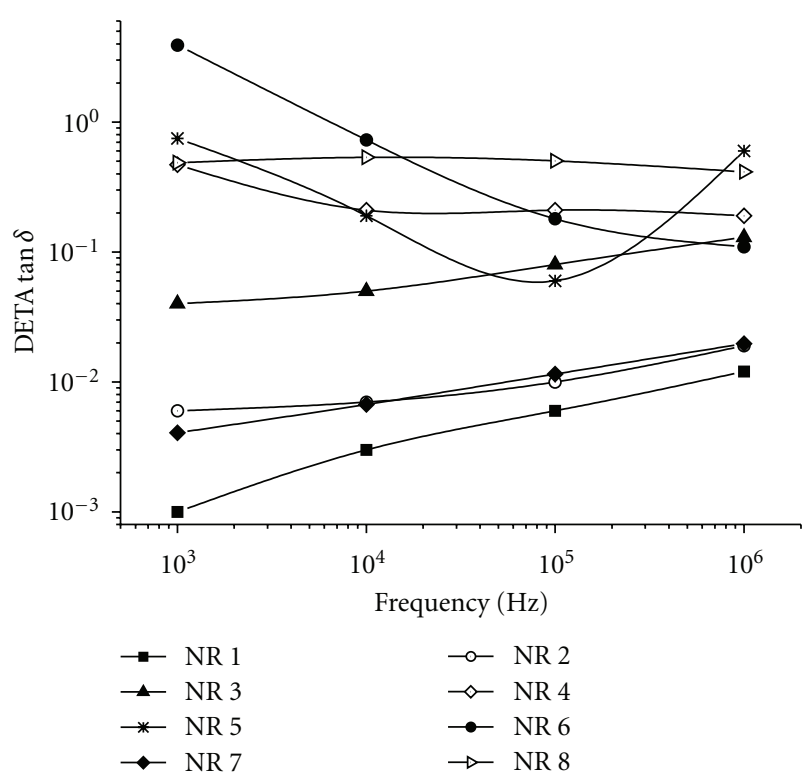

FIGURE 5: Frequency dependence of the dielectric loss angle tangent $($ DETA $\tan \delta$ ) for composites comprising different amounts of Printex XE-2B or Corax N220 at $30^{\circ} \mathrm{C}$.

get closer (e.g., at $100 \mathrm{kHz}$ and $1 \mathrm{MHz}$ ), probably that is due to a passing over the percolation threshold at the given filler amounts as well as to a completed formation of the electroconductive paths. Figures 3 and 4 confirm the significant changes occurring in the dielectric properties of the composites upon their loading with various amounts of carbon black.

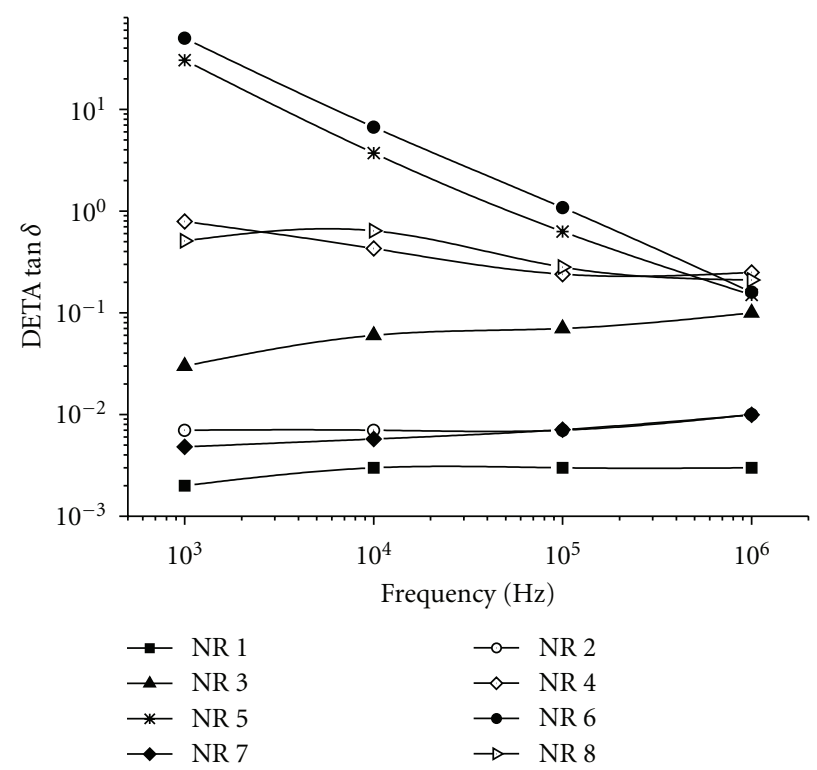

FIGURE 6: Frequency dependence of the dielectric loss angle tangent (DETA $\tan \delta$ ) for composites comprising different amounts of Printex XE-2B or Corax N220 at $80^{\circ} \mathrm{C}$.

Figures 5 and 6 present the vulcanizates dielectric loss angle tangent (DETA $\tan \delta$ ) as a function of frequency studied at different concentrations of Printex XE-2B or Corax N220 carbon black, at $30^{\circ} \mathrm{C}$ and $80^{\circ} \mathrm{C}$. The results for DETA $\tan \delta$ are in agreement with the data obtained for the dielectric permittivity $\left(\varepsilon^{\prime}\right)$. DETA $\tan \delta$ values for the nonfilled composite are in the $10^{-3}-10^{-2}$ range, typical of the polymers possessing dielectric properties. Similarly to the dielectric permittivity $\left(\varepsilon^{\prime}\right)$, DETA $\tan \delta$ decreases with the increasing frequency. The most pronounced effect is at $20 \mathrm{phr}$ carbon black content. We observed different tendencies in the dependence on filler amount and in the dependence on passing over the percolation threshold: with increasing the frequency from $1 \mathrm{kHz}$ to $1 \mathrm{MHz}, \mathrm{DETA} \tan \delta$ increases till reaching the percolation threshold $(7.5 \mathrm{phr})$; when the percolation threshold is passed over DETA $\tan \delta$ decreases in the same frequency range. The most pronounced effect is at $20 \mathrm{phr}$ carbon black content. The comparison of the two figures reveals that at $80^{\circ} \mathrm{C}$ DETA $\tan \delta$ values are significantly higher at passing over the percolation threshold.

3.5. Scanning Electron Microscopy (SEM). Keeping in mind that fillers dispersion may have a significant effect on the composites properties, we used SEM studies to evaluate how well the carbon black fillers were dispersed.

The SEM images presented in Figure 7 show that at any concentration the fillers used are dispersed well and distributed evenly in the matrix. No agglomerates have been observed. The micrographs also reveal the similar dispersion of the fillers Printex XE-2B and Corax N220. Therefore, the effect of different dispersion upon the composites properties may be rulled out. 


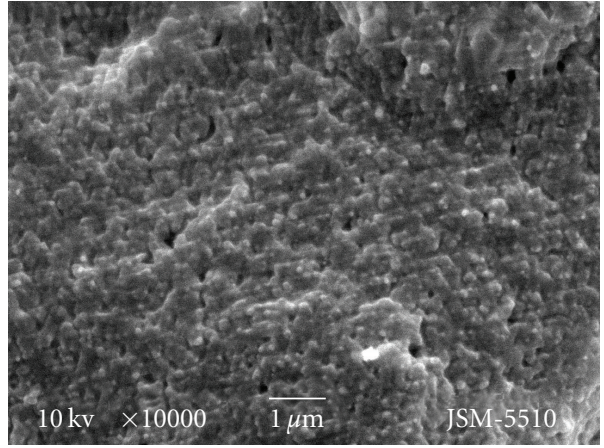

(a)

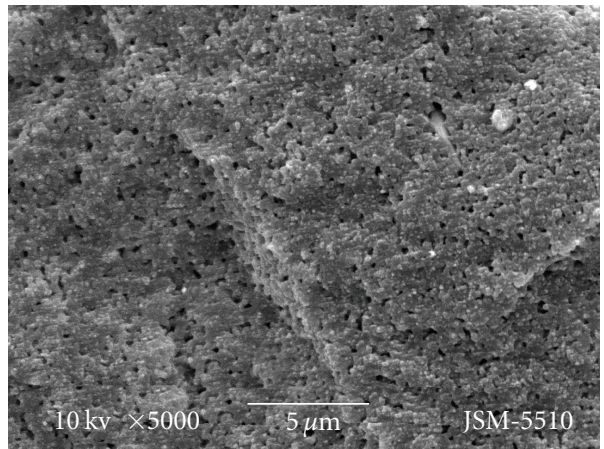

(c)

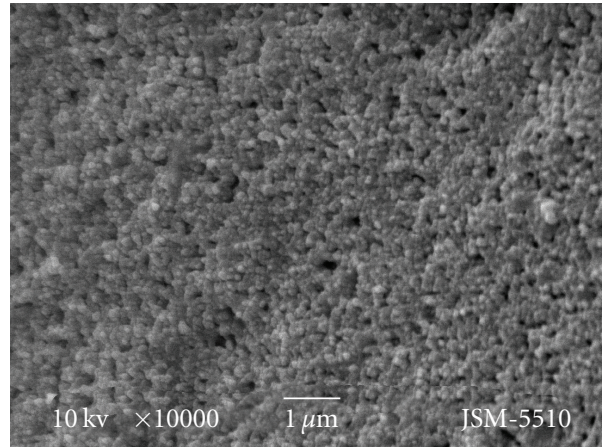

(b)

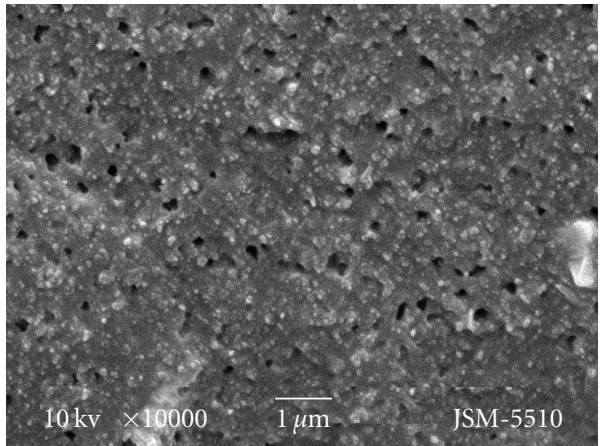

(d)

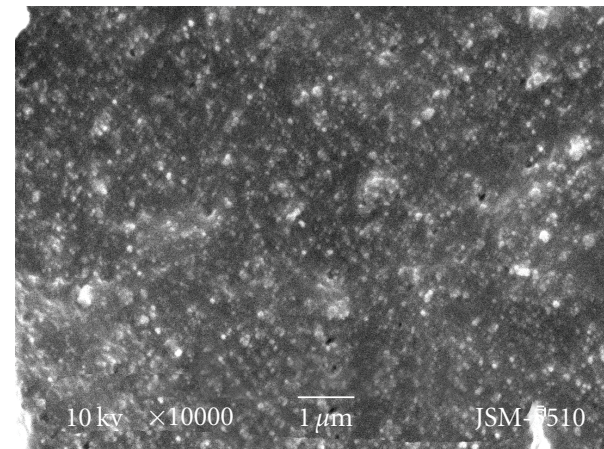

(e)

Figure 7: SEM micrographs of vulcanizates, containing different amounts of fillers: (a) 20 phr of CB Corax N220 ( $\times 10000)$; (b) 50 phr of CB Corax N220 (×10000); (c) 50 phr of CB Corax N220 (×5000); (d) 10 phr of Printex XE-2B (×10000); (e) 20 phr of Printex XE-2B( $\times 10000)$.

\section{Conclusions}

The study presents results from the investigations on the mechanical, dynamic, and dielectric properties of filled natural rubber composites containing furnace Corax N220 carbon black and Printex XE-2B carbon black. The emphasis of the comparative investigations has been put on the influence that the structure and specific surface area of carbon black have on the mentioned-above characteristics. The two types of fillers produce a different effect. It has been established that with regard to some characteristics (minimum (ML) and maximum $(\mathrm{MH})$ torque, tensile strength, temperature interval of glass state, permittivity $\left(\varepsilon^{\prime}\right)$, DETA $\tan \delta$, dispersion, etc.) the rubber compounds filled with Corax N220 at 20 and 50 phr are comparable to those comprising Printex XE-2B carbon black at 510 phr. However, the case is not the same as far as other characteristics like dielectric permittivity $\left(\varepsilon^{\prime}\right)$ are concerned. The dielectric permittivity $\left(\varepsilon^{\prime}\right)$ of the composites comprising Printex XE-2B carbon black at concentrations higher than $7.5 \mathrm{phr}$ reaches up to $10^{2}-10^{4}$. At equal concentration of the two fillers studied, the dielectric permittivity $\left(\varepsilon^{\prime}\right)$ of the vulcanizates comprising Corax N220 carbon black is significantly lower than that of the vulcanizates filled with Printex XE-2B carbon black.

The results obtained reveal that the considerable difference in the structure and specific surface area of the two types of carbon black lead to different dynamic and dielectric properties of the composites investigated. The higher the specific surface area and structure of the filler, the lower its 
concentration needed to achieve comparable characteristics of the composites.

\section{Acknowledgments}

The present research is a result of an international collaboration program between University of Tabuk, Tabuk, Kingdom of Saudi Arabia and the University of Chemical Technology and Metallurgy, Sofia, Bulgaria. The authors gratefully acknowledge the financial support from the University of Tabuk.

\section{References}

[1] J. S. Dick, Rubber Technology-Compounding and Testing for Performance, Hanser, Munich, Germany, 2001.

[2] J. E. Mark, B. Erman, and F. Eirich, Eds., The Science and Technology of Rubber, Elsevier, Amsterdam, The Netherlands, 2005.

[3] Z. M. Dang, H.-T. Song, Y. Q. Lin, and L. J. Ma, "High and low dielectric permittivity polymer-based nanobybrid dielectric films," Journal of Physics: Conference Series, vol. 152, Article ID 012047, 2009.

[4] P. Malinova, R. Nikolov, N. Dishovski, and L. Lakov, "Modification of carbon-containing fillers for elastomers," Kautschuk \& Gummi Kunstst, vol. 57, no. 9, pp. 443-445, 2004.

[5] E. M. Danneberg, "The effects of surface chemical interactions on the properties of Filler-reinforced rubbers," Rubber Chemistry and Technology, vol. 48, p. 410, 1975.

[6] J. Ramier, C. Gauthier, L. Chazeau, L. Stelandre, and L. Guy, "Payne effect in silica-filled styrene-butadiene rubber: influence of surface treatment," Journal of Polymer Science Part B, vol. 45, no. 3, pp. 286-298, 2007.

[7] S. Varghese, J. Karger-Kocsis, and K. G. Gatos, "Melt compounded epoxidized natural rubber/layered silicate nanocomposites: structure-properties relationships," Polymer, vol. 44, no. 14, pp. 3977-3983, 2003.

[8] S. Wolf and M. Wang, Carbon Black, Marcel Dekker, New York, NY, USA, 2nd edition, 1993, Edited by J. B. Donnet. 

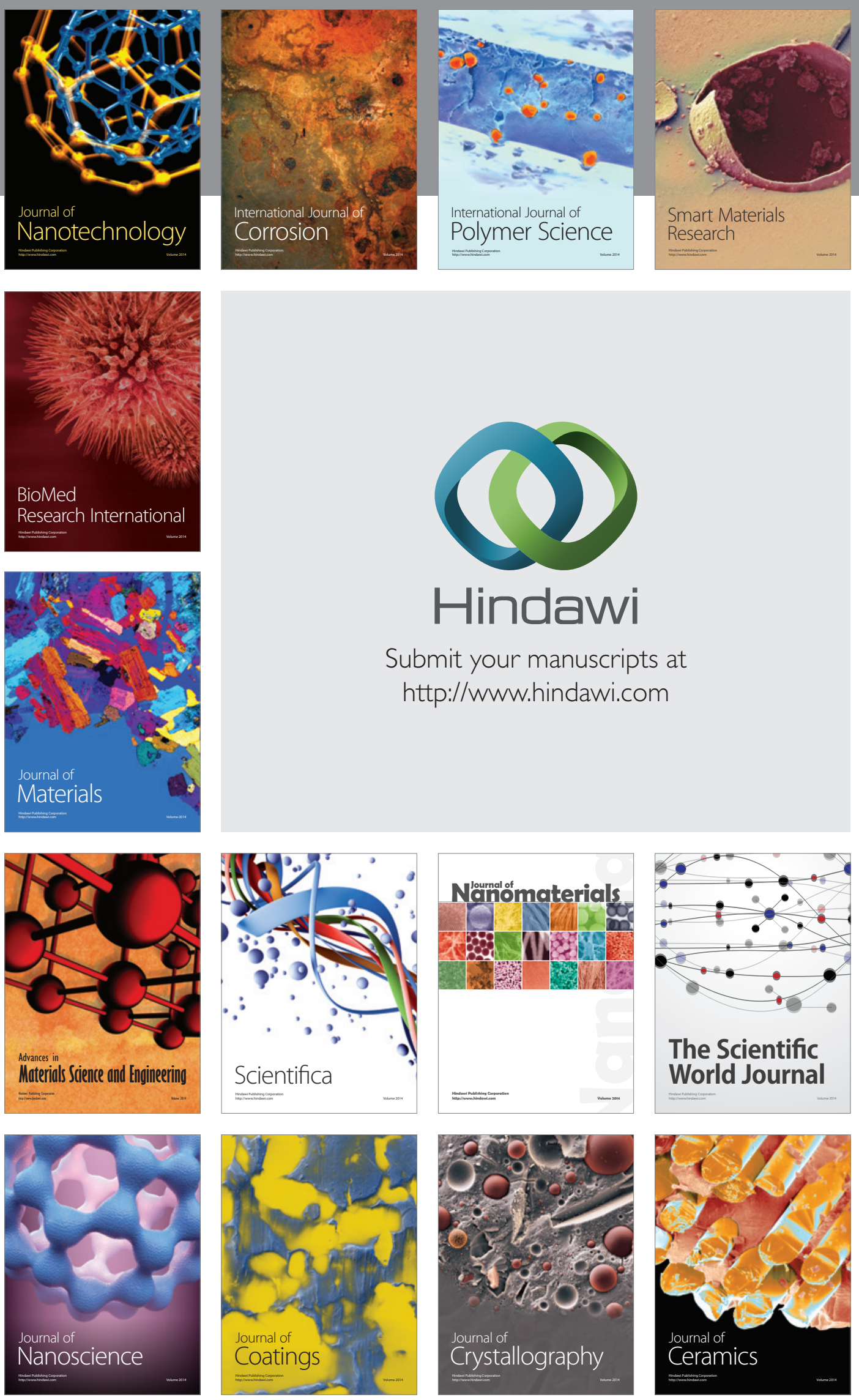

The Scientific World Journal

Submit your manuscripts at

http://www.hindawi.com

\section{World Journal}

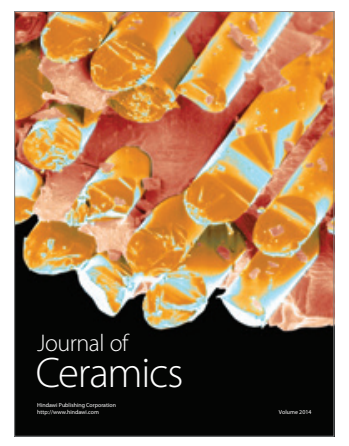

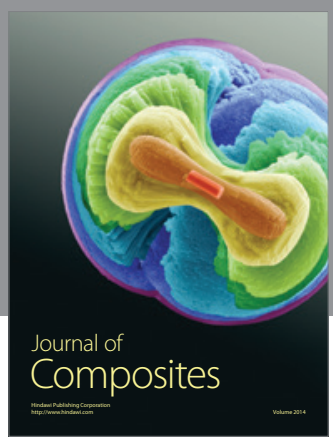
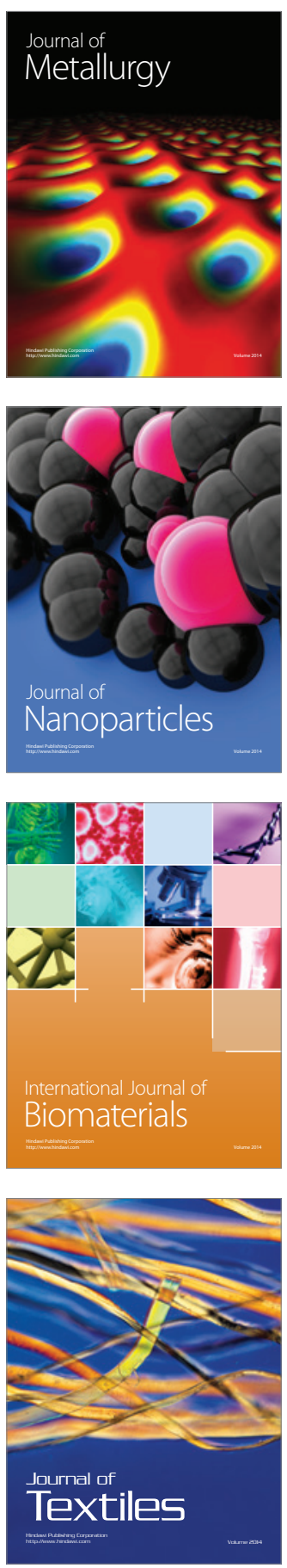